\title{
Time to question the NHS diabetes prevention programme
}

\author{
Public Health England's focus on individual behaviour change is unlikely to stem the epidemic of \\ type 2 diabetes
}

\author{
Eleanor Barry NIHR in-practice fellow ${ }^{1}$, Samantha Roberts DPhil student ${ }^{1}$, Sarah Finer honorary \\ clinical senior lecturer ${ }^{2}$, Shanti Vijayaraghavan consultant diabetologist ${ }^{3}$, Trisha Greenhalgh \\ professor $^{1}$
}

${ }^{1}$ Nuffield Department of Primary Care Health Sciences, University of Oxford, Oxford OX2 6GG, UK; ${ }^{2}$ Blizard Institute, Barts and the London School of Medicine and Dentistry, Queen Mary University of London, London, UK; ${ }^{3}$ Department of Diabetes, Newham University Hospital, Barts Health NHS Trust, London, UK

A new Public Health England report on the rising prevalence of type 2 diabetes proposes targeting people with non-diabetic hyperglycaemia (defined as an $\mathrm{HbA}_{1 \mathrm{c}}$ concentration of 42-47 $\mathrm{mmol} / \mathrm{mol}$ ) with behavioural interventions (diet and exercise). ${ }^{1}$ Action for this group (10.7\% of the adult population) is to be the cornerstone of the NHS Diabetes Prevention Programme, which will be rolled out nationally from $2016 .{ }^{2}$

Such individualised policy is divorced from the multilevel, community-wide, and politically engaged prevention plans recommended by the World Health Organization ${ }^{3}$ and Robert Wood Johnson Foundation. ${ }^{4}$ In its report on non-communicable disease WHO calls for "multisectoral action that simultaneously addresses different sectors that contribute to the production, distribution and marketing of food, while concurrently shaping an environment that facilitates and promotes adequate levels of physical activity.",

Targeting individual behaviour as a preventive strategy rests on five doubtful assumptions: that it is possible, on the basis of a risk score and blood test, accurately to identify a population subgroup with the highest risk of developing diabetes; that individuals thus targeted will behave like participants in research studies; that behaviour changes will be sustained indefinitely; that clinically important improvements in patient relevant outcomes will follow; and that the programme will be affordable and cost effective.

Risk scores and confirmatory tests of hyperglycaemia are imperfect. People excluded on the basis of a risk score (hence, not offered testing) may be falsely reassured.$^{5-8}$ For example, few risk scores ask about a history of gestational diabetes, which disproportionately affects Asian women and increases the risk of type 2 diabetes sevenfold. ${ }^{9}$ Three systematic reviews (not cited in the Public Health England report) were circumspect about the usefulness of diabetes risk scores and warned that a score's external validity may be weak if the population on which it is used differs from the one on which it was developed. ${ }^{578}$

The risk scores were designed to predict type 2 diabetes, but the Public Health England report seems to conflate this with their ability to detect non-diabetic hyperglycaemia. Using $\mathrm{HbA}_{1 \mathrm{c}}$ to identify non-diabetic hyperglycaemia defines twice as many people as "prediabetic" than does the gold standard but impractical oral glucose tolerance test ${ }^{10}$; it may be inaccurate in some groups. ${ }^{11-14}$ Substantial underdiagnosis and overdiagnosis is thus likely, with huge workload implications for both primary care and community services.

Public Health England justifies its proposed policy using a new (non-peer reviewed) meta-analysis of behavioural interventions in diabetes prevention, ${ }^{15}$ which extends a previous meta-analysis. ${ }^{16}$ The 36 primary studies are described-somewhat curiously_as "pragmatic" and "real world." Yet each was limited to a tightly specified individual intervention delivered as part of a research study; half were randomised trials. ${ }^{15}$ Average follow-up was one year. All participants met specific inclusion criteria, including willingness to engage and, in most if not all cases, speaking the same language as the researchers. Individuals drawn from an unselected, free living population are unlikely to respond similarly, given their lower health literacy, higher comorbidities, and greater ethnic diversity, ${ }^{17-19}$ and changes achieved by short term interventions may not be maintained in the longer term..$^{20-22}$ The pathogenesis of diabetes incorporates genetic, physiological, psychological, sociological, and wider environmental influences that play out differently for different individuals in different settings. ${ }^{23}$ Overlooking this complex reality, Public Health England's meta-analysis sought to identify components of behavioural interventions associated with "success," usually measured by surrogate endpoints. For example, it says: "Offering 
13 or more contacts over the first 18 months was associated with a $3.15 \mathrm{~kg}$ greater weight loss in intervention arms compared to control arms, than offering less than eight contacts." 15 Statements of this kind were used to build a specification for a complex intervention that would, its architects assumed, be maximally effective across a diverse population. Implicit in this approach is the flawed assumption that particular components of a complex intervention have a transferable effect size whatever else they are combined with, whoever receives the intervention, and in whatever context. ${ }^{23-26}$

The NHS Diabetes Prevention Programme expects a $26 \%$ reduction in incidence of diabetes and implies that associated morbidity and mortality will fall. Yet the meta-analysis contains no evidence of any sustained reduction in morbidity or mortality relating to diabetes or cardiovascular disease after lifestyle intervention in prediabetes. ${ }^{15}$ Rather, it focuses on changes in surrogate endpoints that were statistically but not clinically significant, such as $\mathrm{HbA}_{1 \mathrm{c}}$ reduction of $0.07 \%$, two hour glucose reduction of $0.28 \mathrm{mmol} / \mathrm{l}$, and weight reduction of $1.57 \mathrm{~kg} .{ }^{15} \mathrm{~A}$ newly published evidence synthesis of the effect of lifestyle interventions on overall mortality in prediabetes cites 17 trials that failed to show a significant effect and one that just reached statistical significance. ${ }^{27}$ Effects tend to be far smaller in unselected free living populations than in trial participants. ${ }^{28}$

Astonishingly, given that this lifestyle intervention will become national policy, the Public Health England reports offer no formal estimate of the programme's cost or cost effectiveness. The assumption that it will save money is based on speculation that the intervention will produce "optimal effects whilst keeping costs to a minimum." 15 The proposed payment by results model may create perverse incentives to focus on "compliant" populations rather than those at greatest risk of diabetes, which often experience multiple barriers to achieving the desired outcomes. ${ }^{29} 30$

The public consultation on England's proposed NHS Diabetes Prevention Programme runs until 18 September 2015 (www. england.nhs.uk/ourwork/qual-clin-lead/action-for-diabetes/ diabetes-prevention). We have serious concerns that the programme consists entirely of a top down, highly standardised behavioural intervention offered to a fraction of the population. Public Health England's estimates suggest that $18.2 \%$ of adults in England now have abnormal glucose metabolism (10.7\% prediabetic, $7.5 \%$ diabetic) and that this figure is rising. This surely necessitates investment in population based strategies such as improving the neighbourhood environments for healthy food choices and physical activity opportunities as well as support for individuals. ${ }^{10293031}$ Readers who share our concerns may wish to contribute their views to the consultation.

Competing interests: We have read and understood BMJ policy on declaration of interests and declare we are all clinical academics who are working with Newham Clinical Commissioning Group and other local partners to design a multifaceted community based diabetes prevention programme for an ethnically diverse and deprived local population.
Provenance and peer review: Not commissioned; externally peer reviewed.

1 National Cardiovascular Intelligence Network. NHS Diabetes Prevention Programme (NHS DPP) Non-diabetic hyperglycaemia . Public Health England, 2015.

2 NHS England. NHS Diabetes Prevention Programme. 2015. www.england.nhs.uk/ourwork qual-clin-lead/action-for-diabetes/diabetes-prevention/.

3 World Health Organisation. Global status report on noncommunicable diseases 2014 www.who.int/nmh/publications/ncd-status-report-2014/en/.

4 Green T. Diabetes-the case for considering context . 2015. www.rwif.org/en/culture-ofhealth/2015/01/diabetes the casef.html.

5 Buijsse B, Simmons RK, Griffin SJ, et al. Risk assessment tools for identifying individuals at risk of developing type 2 diabetes. Epidemiol Rev 2011;33:46-62.

6 Kengne AP, Beulens JW, Peelen LM, et al. Non-invasive risk scores for prediction of type 2 diabetes (EPIC-InterAct): a validation of existing models. Lancet Diabetes Endocrinol 2014;2:19-29.

7 Noble D, Mathur R, Dent T, et al. Risk models and scores for type 2 diabetes: systematic review. BMJ 2011;343:d7163.

8 Collins GS, Mallett S, Omar O, et al. Developing risk prediction models for type 2 diabetes: a systematic review of methodology and reporting. BMC Med 2011;9:103.

9 Bellamy L, Casas J-P, Hingorani AD, et al. Type 2 diabetes mellitus after gestational diabetes: a systematic review and meta-analysis. Lancet 2009;373:1773-9.

10 Yudkin JS, Montori VM. The epidemic of pre-diabetes: the medicine and the politics. BMJ 2014;349:g4485.

11 Selvin E, Rawlings AM, Bergenstal RM, et al. No racial differences in the association of glycated hemoglobin with kidney disease and cardiovascular outcomes. Diabetes Care 2013;36:2995-3001

12 Kim C, Bullard KM, Herman WH, et al. Association between iron deficiency and A1C Levels among adults without diabetes in the National Health and Nutrition Examination Survey, 1999-2006. Diabetes Care 2010;33:780-5.

13 Kim PS, Woods C, Georgoff $\mathrm{P}$, et al. A1C underestimates glycemia in HIV infection. Diabetes Care 2009;32:1591-3.

14 Behan KJ, Merschen J. HbA1c does not always estimate average glucose. Clin Lab Sci 2011;24:71-7.

15 Ashra NB, Spong R, Carter P, et al. A systematic review and meta- analysis assessing the effectiveness of pragmatic lifestyle interventions for the prevention of type 2 diabetes mellitus in routine practice. 2015. www.gov.uk/government/publications/diabetesprevention-programmes-evidence-review.

16 Dunkley AJ, Bodicoat DH, Greaves CJ, et al. Diabetes prevention in the real world: effectiveness of pragmatic lifestyle interventions for the prevention of type 2 diabetes and of the impact of adherence to guideline recommendations a systematic review and meta-analysis. Diabetes Care 2014;37:922-33.

17 Rothwell PM. External validity of randomised controlled trials:"to whom do the results of this trial apply?" Lancet 2005;365:82-93.

18 Society for Women's Health Research, United States Food and Drug Administration Office of Women's Health. Dialogues on diversifying clinical trials . 2012. www.fda.gov/downloads/ scienceresearch/specialtopics/womenshealthresearch/ucm334959.pdf.

19 Ford JG, Howerton MW, Lai GY, et al. Barriers to recruiting underrepresented populations to cancer clinical trials: a systematic review. Cancer 2008;112:228-42.

20 Yates T, Davies M, Gorely T, et al. Effectiveness of a pragmatic education program designed to promote walking activity in individuals with impaired glucose tolerance a randomized controlled trial. Diabetes Care 2009;32:1404-10.

21 Bhopal RS, Douglas A, Wallia S, et al. Effect of a lifestyle intervention on weight change in south Asian individuals in the UK at high risk of type 2 diabetes: a family-cluster randomised controlled trial. Lancet Diabetes Endocrinol 2014;2:218-27.

22 Oldroyd JC, Unwin NC, White M, et al. Randomised controlled trial evaluating lifestyle interventions in people with impaired glucose tolerance. Diabetes Res Clin Pract 2006;72:117-27.

23 Cohn S, Clinch M, Bunn C, et al. Entangled complexity: why complex interventions are just not complicated enough. J Health Serv Res Policy 2013;18:40-3.

24 Mackenzie M, O'Donnell C, Halliday E, et al. Do health improvement programmes fit with MRC guidance on evaluating complex interventions? BMJ 2010;340:c185.

25 Petticrew M. When are complex interventions "complex"? When are simple interventions "simple"? Eur J Public Health 2011;21:397-8.

26 Hawe P. Lessons from complex interventions to improve health. Public Health 2015;36:307.

27 Selph S, Dana T, Blazina I, et al. Screening for type 2 diabetes mellitus: a systematic review for the US Preventive Services Task Force. Ann Intern Med 2015;162:765-76.

28 Ioannidis JP. Why most published research findings are false. PLoS Med 2005;2:e124.

29 Hill JO, Galloway JM, Goley A, et al. Scientific statement: socioecological determinants of prediabetes and type 2 diabetes. Diabetes Care 2013;36:2430-9.

30 Unwin N, Whiting D, Roglic G. Social determinants of diabetes and challenges of prevention. Lancet 2010;375:2204-5.

31 Christine PJ, Auchincloss AH, Bertoni AG, et al. Longitudinal associations between neighborhood physical and social environments and incident type 2 diabetes mellitus: the Multi-Ethnic Study of Atherosclerosis (MESA). JAMA Intern Med 2015;175:1311-20.

Cite this as: BMJ 2015:351:h4717

(c) BMJ Publishing Group Ltd 2015 